\title{
Formulation and Evaluation of Multipurpose Herbal Cream
}

\author{
Akash S. Mali ${ }^{1}$, Karekar $P^{2}$, Dr. Yadav A. $\mathbf{V}^{3}$ \\ Gourishankar Institute of Pharmaceutical Education and Research Limb, Satara, Maharashtra, India
}

\begin{abstract}
Herbal cosmetics are the preparations used to enhance the human appearance. The aim of the present research was to formulate the herbal Cream for the purpose of Moistening, Nourishing, lightening \& Treatment of various diseases of the skin. Different crude drugs; Aloe barbadensis (Aloe Vera leaves), Ocimum Sanctum (Tulsi-leaves), Azadirachta Indica (Neem-leaves), Curcuma longa (Turmeric-rhizomes), Cedro Oil(Lemon Peel), Myristica fragrans(Nutmeg seeds), Olium rosae(Rose Oil), Orange Oil, Prunus dulcis (Almond oil) were taken. Accelerated stability testing of two final sample has been conducted in the environmental chamber with temperature $25 \pm 1^{0} \mathrm{C}$ and humidity $60 \pm 10 \% \mathrm{RH}$. All the products were found to be stable with no sign of phase separation and no change in the color. The patch test for sensitivity testing has also been done and no evidence of skin irritation and allergic signs. This work mainly focuses on the assessment of the microbial quality of Formulated cosmetic preparations. To the surprise, both formulations was found to comply with the microbial limit tests as per the international specifications. Thus herbal cosmetics formulation is safe to use was proved and it can be used as the provision of a barrier to protect skin.
\end{abstract}

Keywords: Herbal cream, Anti ageing, Cosmeceutical, Microbial Stability

\section{Introduction}

The concept of beauty and cosmetics is as ancient as mankind and civilization. Indian herbs and its significance are popular worldwide. An herbal cosmetic have growing demand in the world market and is an invaluable gift of nature. Herbal formulations always have attracted considerable attention because of their good activity and comparatively lesser or nil side effects with synthetic drugs. Herbal cosmetics are defined as the beauty products which posses desirable physiological activity such as healing, smoothing appearance, enhancing and conditioning properties because of herbal ingredient. Now-a-days the usefulness of herbs in the cosmeceutical production has been extensively increased in personal care system and there is a great demand for the herbal cosmetics.Cosmetics are the substances intended to be applied to the human body for cleansing, beautifying, promoting attractiveness, and altering the appearance without affecting the body's structure or functions. But the usage of synthetic products becomes very harmful from long time for the youth as well as our environment. Various synthetic compounds, chemicals, dye and their derivative proved to cause various skin diseases having numerous side effects. Thus we are using herbal cosmetics as much as possible. The basic idea of skin care cosmetic lies deep in the Rigveda, Yajurveda, Ayurveda, Unani and Homeopathic system of medicine. These are the products in which herbs are used in crude or extract form. These herbs should have varieties of properties like antioxidant, anti-inflammatory, antiseptic, emollient, anti seborrhatic, antikerolytic activity and antibacterial etc. Cosmetics are developed to reduce wrinkles, fight acne and to control oil secretion. For various types of skin ailments formulations like skin protective, sunscreen, antiacne, antiwrinkle and antiaging are designed using varieties of materials, either natural or synthetic. Cream is a polyherbal formulation that consists of extracts of Aloe barbadensis, Ocimum sanctum, Azadirachta indica, Curcuma longa, Cedro oil, Myristica fragrans, Olium rosae(Rose Oil), Orange Oil, Prunus dulcis, Ocimum sanctum. These herbs have been selected on the basis of a traditional system and scientific justification with modern uses. A herbal lotion that can give effective protection to skin and free from any toxicity or toxic residue or any irritation when regularly used and should also be cosmetically acceptable.

\section{Experimental}

\section{Preparation of Extracts-}

All the Herbals were weighed accurately \& aqueous extraction had been done (10 times of the weight of the drug i.e. $5 \mathrm{~g}$ in $50 \mathrm{ml}$ of water on water bath at $80-100^{\circ} \mathrm{C}^{\text {) }}$. As the solution concentrated up to $20 \mathrm{ml}$, filtration was done. Residue had been taken \& volume was making up to $40 \mathrm{ml}$, again boiled. After remaining $20 \mathrm{ml}$ was filtered and collected in the form of powder and the same procedure was followed again.(Figure 1)

\section{Formulation Preparation-}

The formulation components used were listed in Table 2. Oil in water emulsion of 20 and $60 \%$ of drugs were formulated. The emulsifier (glycerol monostearate) and other oil soluble components (petroleum jelly, Cetyl alcohol) were dissolved in the oil phase (Part A) and heated up to $80^{\circ} \mathrm{C}$. Extract and water soluble components (Methyl paraban, Propyl paraban) were dissolved in (Part B) and heated up to $80^{\circ} \mathrm{C}$. After heating, the aqueous phase was added in portions to the oil phase with constant stirring until cream is formed, And cream was formulated Having superb color i.e. Lemon yellow. Perfume was added when the temperature dropped to $45{ }^{\circ} \mathrm{C} \pm 50^{\circ} \mathrm{C}$

\section{Evaluation of Cream}

1) Physical Properties- The Cream was observed for color, odour and appearance.

2)Test for Thermal Stability -Thermal stability of the formulation was determined by the humidity chamber controlled at $60-70 \% \mathrm{RH}$ and $37 \pm 1{ }^{\circ} \mathrm{C}$

3)Determination of $\mathbf{p H}-5 \pm 0.01 \mathrm{~g}$ of the Cream was weighed accurately in a $100 \mathrm{ml}$ beaker. $45 \mathrm{ml}$ of water was 


\section{International Journal of Science and Research (IJSR) \\ ISSN (Online): 2319-7064 \\ Index Copernicus Value (2013): 6.14 | Impact Factor (2014): 5.611}

added \& dispersed the Cream in it. The $\mathrm{pH}$ of the suspension was determined at $27^{\circ} \mathrm{C}$ using the $\mathrm{pH}$ meter.

4)Stability studies- Stability testing of drug products begins as a part of drug discovery and ends with the demise of the compound or commercial product. To assess the drug and formulation stability, stability studies were done according to ICH guidelines. The stability studies were carried out as per ICH guidelines. The cream filled in bottle and kept in humidity chamber maintained at $30 \pm 2{ }^{\circ} \mathrm{C} / 65 \pm 5 \% \mathrm{RH}$ and $40 \pm 2{ }^{\circ} \mathrm{C} / 75 \pm 5 \% \mathrm{RH}$ for two months. At the end of studies, samples were analyzed for the physical properties and viscosity.

5)Patch Test - About 1-3gm of material to be tested was placed on a piece of fabric or funnel and applied to the sensitive part of the skin e.g. skin behind ears. The cosmetic to be tested was applied to an area of 1sq.m.of the skin. Control patches were also applied. The site of patch is inspected after $24 \mathrm{hrs}$.

6)Spreadability studies - An important criteria for semisolids is that it posses good spreadability. Spreadability is a term expressed to denote the extent of area to which the cream readily spreads on application to the skin. The therapeutic efficacy of a formulation also depends on its spreading value. A special apparatus has been designed to study the spreadability of the formulations. Spreadability is expressed in terms of time in seconds taken by two slides to slip off from the formulation, placed between, under the application of a certain load. Lesser the time taken for the separation of the two, better the spreadability. Two glass slides of standard dimensions were selected. The formulation whose spreadability had to be determined was placed over one of the slides. The other slide was placed on top of the formulations was sandwiched between the two slides across the length of $5 \mathrm{~cm}$ along the slide. $100 \mathrm{~g}$ weight was placed up on the upper slide so that the formulation between the two slides was pressed uniformly to form a thin layer. The weight was removed and the excess of formulation adhering to the slides was scrapped off. One of the slides was fixed on which the formulation was placed. The second movable slide was placed over it, with one end tied to a string to which load could be applied by the help of a simple pulley and a pan. A $30 \mathrm{~g}$ weight was put on the pan and the time taken for the upper slide to travel the distance of $5.0 \mathrm{~cm}$ and separate away from the lower slide under the direction of the weight was noted. The spreadability was then calculated from the following formula:

\section{Spreadability $=\mathbf{m} \times \mathbf{l} / \mathbf{t}$}

$\mathrm{m}=$ weight tied to the upper slide $(30 \mathrm{~g}) \mathrm{l}=$ length of glass slide $(5 \mathrm{~cm}) \mathrm{t}=$ time taken in seconds

7)Test for microbial growth in formulated creams- The formulated creams were inoculated on the plates of agar media by streak plate method and a control was prepared by omitting the cream. The plates were placed in to the incubator and are incubated at $37{ }^{\circ} \mathrm{C}$ for 24 hours. After the incubation period, plates were taken out and check the microbial growth by comparing it with the control.

\section{Result and Discussion}

A majority of the world's population in developing countries still relies on herbal medicine to meet its health needs and because of this extensive research is now being carried out in this area. The $\mathrm{pH}$ of the prepared cream with the extract was found to be around 6 which is suitable for topical application because the $\mathrm{pH}$ of the skin is between $4.5-6$. The spreadability studies showed that formulation have better spreadability when compared with the marketed cream. Which is perfectly challenged to Marketed Creams. The results of $\mathrm{pH}$ and spreadability are summarized in table no.8. The stability studies of the various parameters like visual appearance, nature, $\mathrm{pH}$ of the formulations showed that there was no significant variation after two months of the study period and the results are summarized in table no. 7. The formulation $20 \%$ and $60 \%$ shows no redness, edema, inflammation and irritation during Patch Test studies. These formulations are safe to use for skin. The formulated creams were tested for the presence of pathogenic microorganisms by culturing it with agar medium.(Figure 2) There were no signs of microbial growth after incubation period of 24 hours at $37^{\circ} \mathrm{C}$ and having more antimicrobial property as compare to standard.

\section{Conclusion}

The present work focuses on the potential of herbal extracts from cosmetic purposes. The uses of cosmetic have been increased in many folds in personal care system. The use of bioactive ingredients in cosmetic influence biological functions of skins and provide nutrients necessary for the healthy skin. The prepared formulations showed good spreadability, no evidence of phase separation and good consistency during the study period. Stability parameters like visual appearance, nature and fragrance of the formulations showed that there was no significant variation during the study period.

Table 1: Uses of Ingredients

All Ingredient are collected from Satara near region

\begin{tabular}{|c|c|c|}
\hline S. No & Ingredient & Uses \\
\hline 1 & Lemon Oil & $\begin{array}{c}\text { As flavor, stimulant, carminative, } \\
\text { stomachic, cleanser. }\end{array}$ \\
\hline 2 & Aloe & $\begin{array}{c}\text { Hydrating agent, emollient, anti-wrinkles, } \\
\text { wound healer. }\end{array}$ \\
\hline 3 & Turmeric & $\begin{array}{c}\text { Antimicrobial agent, lightning agent, } \\
\text { moisturizer. }\end{array}$ \\
\hline 4 & Tulsi & Antimicrobial agent. \\
\hline 5 & Nutmeg & Flavoring agent, carminative, antispot. \\
\hline 6 & Rose Water & Flavoring agent, cooling agent, emollient. \\
\hline 7 & Neem leaves & $\begin{array}{c}\text { Treatment on Ecema, ring worm infection, } \\
\text { scabies, psoriasis. }\end{array}$ \\
\hline 8 & Orange oil & Anti skin cancer agent, black spot reducer. \\
\hline 9 & Almond oil & Antiwrinkle, moisturizer, as flavor. \\
\hline
\end{tabular}

Table 2: Formulas

\begin{tabular}{|c|c|c|c|}
\hline Sr No. & Ingredients & Extract 20\% & Extract 60\% \\
\hline 1 & Lemon Oil & 0.40 & 1.35 \\
\hline 2 & Aloe & 0.25 & 0.75 \\
\hline 3 & Turmeric & 0.20 & 0.60 \\
\hline 4 & Tulsi & 0.30 & 0.60 \\
\hline 5 & Nutmeg & 0.30 & 0.60 \\
\hline 6 & Rose Water & 0.10 & 0.30 \\
\hline 7 & Nem leaves & 0.35 & 1.05 \\
\hline 8 & Orange oil & 0.10 & 0.30 \\
\hline 9 & Almond oil & 0.10 & 0.30 \\
\hline
\end{tabular}




\section{International Journal of Science and Research (IJSR) \\ ISSN (Online): 2319-7064 \\ Index Copernicus Value (2013): 6.14 | Impact Factor (2014): 5.611}

Table 3: Composition of Cream

\begin{tabular}{|c|c|c|c|}
\hline Sr. No. & Ingredient & \multicolumn{2}{|c|}{ Composition } \\
\cline { 3 - 4 } & & $20 \%$ & $60 \%$ \\
\hline 1 & Extract & $2 \mathrm{gm}$ & $6 \mathrm{gm}$ \\
\hline 2 & Petrolium gelly & $4.3 \mathrm{gm}$ & $2.2 \mathrm{gm}$ \\
\hline 3 & Hard paraffin & $2 \mathrm{gm}$ & $1.1 \mathrm{gm}$ \\
\hline 4 & Cetyl alcohol & $0.5 \mathrm{ml}$ & $0.2 \mathrm{ml}$ \\
\hline 5 & Glyceryl mono sterate & $0.5 \mathrm{gm}$ & $0.2 \mathrm{gm}$ \\
\hline 6 & Methyl Paraben & $0.4 \mathrm{gm}$ & $0.2 \mathrm{gm}$ \\
\hline 7 & Propyl paraben & $0.3 \mathrm{gm}$ & $0.1 \mathrm{gm}$ \\
\hline 8 & Fragrance & q.s. & q.s. \\
\hline 9 & Activated Charcoal & $0.01 \mathrm{gm}$ & $0.01 \mathrm{gm}$ \\
\hline
\end{tabular}

Quantitative standards of all the drug components were carried out as per The Ayurvedic pharmacopoeia of India (API) methods and compared with API standards.

Table 4: Quantitative standards

\begin{tabular}{|c|c|c|c|c|c|}
\hline Parameter/Drugs & $\begin{array}{c}\text { Foreign matter } \\
(\mathrm{mg}) \% \mathrm{w} / \mathrm{w}\end{array}$ & $\mathrm{pH}$ & $\begin{array}{c}\text { Water Soluble } \\
\text { Extractive } \% \mathrm{w} / \mathrm{v}\end{array}$ & $\begin{array}{c}\text { Alcohol Soluble } \\
\text { Extractive \% } \mathrm{w} / \mathrm{v}\end{array}$ & $\begin{array}{c}\text { Reference (compliance } \\
\text { with) }\end{array}$ \\
\hline Lemon Oil & 0.2 & $2-3$ & 0.1 & 0.7 & API Part I Vol I \\
\hline Aloe & 1.3 & 6.10 & 7.9 & 2.8 & API Part I Vol II \\
\hline Turmeric & 0.3 & 5.71 & 12.24 & 0.65 & API Part I Vol II \\
\hline Tulsi & 0.7 & 5.59 & 14.36 & 2.24 & API Part I Vol II \\
\hline Nutmeg & 1.3 & 5.7 & 12.7 & 0.9 & API Part I Vol II \\
\hline Rose Water & 0.1 & 6.2 & 24.1 & 1.9 & API Part I Vol II \\
\hline Neem leaves & 1.7 & 6.65 & 18.83 & 0.589 & API Part I Vol II \\
\hline Orange oil & 0.1 & 3.7 & 5.4 & 5.3 & API Part I Vol I \\
\hline Almond oil & 0.05 & 4.63 & 4.8 & 4.9 & API Part I Vol II \\
\hline
\end{tabular}

Table 5: Physical Properties of herbal Cream

\begin{tabular}{|c|c|c|c|}
\hline Sr. no. & Properties & $20 \%$ & $60 \%$ \\
\hline 1 & Colour & Pale Yellow & Pale Yellow \\
\hline 2 & Odour & Characteristis & Characteristis \\
\hline 3 & Appearance & Semi -solid & Semi-solid \\
\hline
\end{tabular}

Table 6: Thermal stability and $\mathrm{pH}$ Determination

\begin{tabular}{|c|c|c|c|}
\hline Sr.No. & TEST & $20 \%$ & $60 \%$ \\
\hline 1 & $\begin{array}{c}\text { Thermal Stability (at } \\
\text { RH } 65 \% \\
\text { and } 30 \pm 40 \mathrm{oC})\end{array}$ & $\begin{array}{c}\text { Stable, no oil } \\
\text { separation }\end{array}$ & $\begin{array}{c}\text { Stable, no oil } \\
\text { separation }\end{array}$ \\
\hline 2 & $\mathrm{pH}($ at $27 \mathrm{oC} \pm 2 \mathrm{oC})$ & 6.03 & 5.58 \\
\hline
\end{tabular}

Table 7: Accerlated Stability Studies

\begin{tabular}{|c|c|c|c|c|c|c|}
\hline \multirow{2}{*}{ MONTHS/ TESTS } & \multicolumn{3}{|c|}{ Harbal cream (20\%) } & \multicolumn{3}{|c|}{ Harbal cream $(60 \%)$} \\
\hline & Initial month & After-1 month & After - 2 month & Initial month & After - 1 month & After - 2 month \\
\hline Physical appearance & Semi-solid & Semi-solid & Semi-solid & Semi-solid & Semi-solid & Semi-solid \\
\hline Texture & Ok & Ok & $\mathrm{Ok}$ & Ok & $\mathrm{Ok}$ & Ok \\
\hline colour & Lemon yellow & Lemon yellow & Lemon yellow & Lemon yellow & Lemon yellow & Lemon yellow \\
\hline Odour & Characteristic & Characteristic & Characteristic & Characteristic & Characteristic & Characteristic \\
\hline $\mathrm{pH}$ value & 5.8 & 5.9 & 5.9 & 6.2 & 6.2 & 6.2 \\
\hline Thermal stability & ok & ok & ok & ok & ok & Ok \\
\hline Degradation of produc & nil & nil & nil & nil & nil & nil \\
\hline
\end{tabular}

Accelerated stability testing of prepared formulations i.e. $20 \%$ and $60 \%$ were conducted at $40 \pm 20 \mathrm{C}$ temperature and $75 \pm 5 \%$ relative humidity and studied for 60 days.

Table 8: Spredability Test

\begin{tabular}{|c|c|c|}
\hline Formulations & Time $(\mathrm{sec})$ & Spreadability $(\mathrm{g} \mathrm{cm} / \mathrm{sec})$ \\
\hline $20 \%$ cream & 15 & 14.6 \\
\hline $60 \%$ cream & 14 & 13.3 \\
\hline Marketed cream & 15 & 13.5 \\
\hline
\end{tabular}
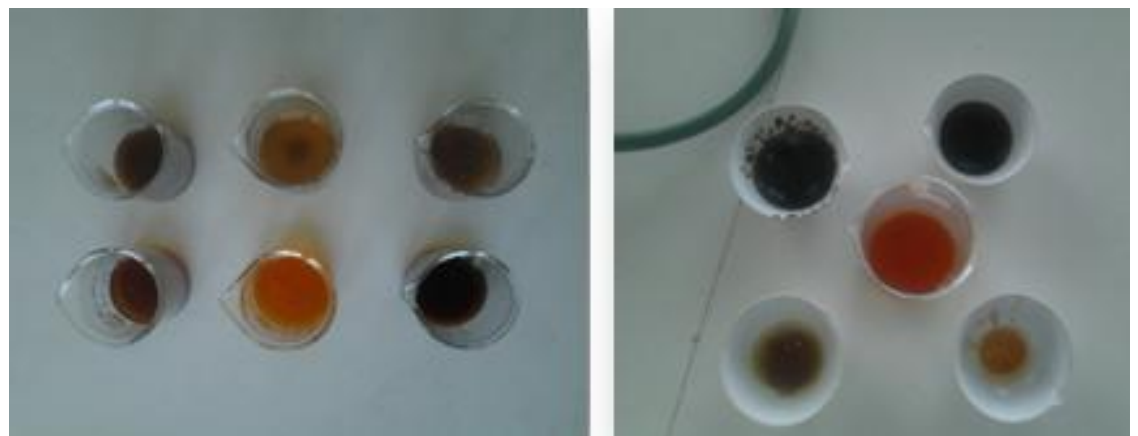

Figure 1: Extract of Herbal Ingredients

Volume 4 Issue 11, November 2015 


\section{International Journal of Science and Research (IJSR) \\ ISSN (Online): 2319-7064}

Index Copernicus Value (2013): 6.14 | Impact Factor (2014): 5.611

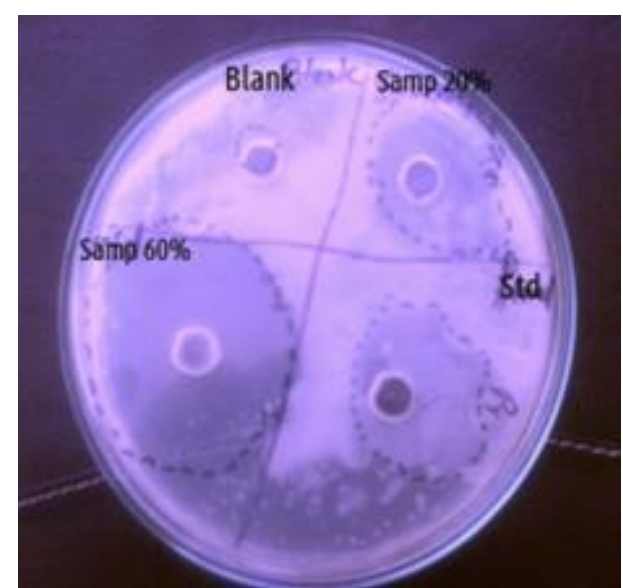

creamagainst UV radiation induced damage, Trend In Medical Research, 2: 135-141, (2007).

[12] Note For Guidance on Stability Testing. Stability Testing of New Drug Substances and Products

[13] Bronaugh, R.L. and Naibach, H.I., " topical absorption of dermatological products." Marcel dekk.

Figure 2: Photograph showing Microbial count

\section{Acknowledgement}

The Authors is Thankful to the guide Miss Karekar P.S., Head of Department Mr. Gurav Y. A. \& Staff of GIPER, LIMB, SATARA for providing necessary facilities to carry out this Work.

\section{References}

[1] Kawada A, Konishi N, Momma T, Oiso N, Kawara S. Evaluation of anti-wrinkle effects of a novel cosmetic containing Niacinamide. J Dermatol 2008;35:637-642

[2] MarieLode N, Buraczewska I, Halvarsson K. Facial anti-wrinkle cream: influence of product presentation on effectiveness: a randomized and controlled study. Skin Res Technol 2007; 13:189-194.

[3] Evans WC, Trease GE, Pharmacognosy, Bailleire tindall East bourne, 15 th ed, UK,

[4] 156, 256 (1996).

[5] Jawaid Talha, Gupta Rol and Siddiqui Zohaib Ahmed, A review on herbal plants showing antidepressant activity. International Journal of Pharmaceutical Science and Research, 2: 3051-3060, (2011).

[6] Kausik Biswas, Ishita Chattopadhyay, Ranajit K. Banerjee and Uday Bandyopadhyay, Biological activities and medicinal properties of neem (Azadirachtaindica). Current Science, 82: 1336-1345, (2002).

[7] V. V. Paithankar, Formulation and evaluation of herbal cosmetic preparation using safed musli. International Journal of PharmTech Research, 2 (4): 2261-2264, (2010).

[8] Babu, Novel herbal composition for treatment of psoriasis and other skindisorders, U.S. Patent US 0165136, 2011

[9] Maithani Alok, Azadirachta indica (neem) leaf: a review. Journal of Pharmacy Research, 4(6): 18241827, (2011).

[10] Vishwakarma Bharat, Dwivedi Sumeet, Dubey Kushagra, and Joshi Hemant Formulation and evaluation of herballipstick. International Journal of Drug Discovery and Herbal Research, 1(1): 18-19, (2011).

[11] Ashawat M.S, Saraf Shailendra and SarafSwarnlata, Biochemical andhistopathological studies of herbal 